48\%. There were several risk factor of it, such as night work or psychological demand.

Conclusion This review of the literature showed the prevalence of work-related disorders among hospital doctors. The risk factors studied can guide prevention policies within hospitals.

\section{OCCUPATIONAL DISEASES OF MEDICAL LABORATORY STAFF: REVIEW OF LITERATURE 2006-2016}

${ }^{1,2} \mathrm{R}$ Pougnet, ${ }^{3} \mathrm{M}$ Uguen, ${ }^{1,4} \mathrm{~B}$ Loddé, ${ }^{1} \mathrm{~B}$ Sawicki, ${ }^{5,6} \mathrm{~L}$ Pougnet. ${ }^{1}$ Centre de Pathologies Maritimes, Environnementales et Professionnelles; Médecine du Travail du Personnel Hospitalier, CHRU de Brest; ${ }^{2} E A 4686$ Ethique, Professionnalisme et Santé, Université de Bretagne Occidentale, Brest; ${ }^{3}$ Service de Santé au Travail en Iroise, Brest; ${ }^{4}$ EA 4324 Optimisation des Régulations Physiologiques (ORPHY), Université de Bretagne Occidentale, Brest; ${ }^{5}$ Laboratoire de Biologie Médicale, Hôpital d'Instruction des Armées, ClermontTonnerre, Brest

\subsection{6/oemed-2018-ICOHabstracts.1097}

Introduction The trade of laboratory technician (TL) exposes to many risks to health, because of biological or chemical or physical exposures. But the TL occupation is constantly evolving, the techniques are constantly changing. The purpose of this article is to take stock of the occupational TL pathologies which were recently described in the literature.

Material and method This is a literature review, based on Medline and Scopus medical databases, on publications between 01/01/2006 and 31/12/2016. The research was conducted in French and English. Only articles about TL in Hospital or Teaching Hospital were selected.

Results Twenty-eight articles were studied. The main infectious pathology described was brucellosis; A case of meningitis was studied. The cutaneous allergies reported concerned sensitisation to certain solvents. There was no allergy to latex. Musculoskeletal disorders (MSD) were studied in 4 articles. The main MSDs were low back pain and neck pain. Several articles have been alerted on the occurrence of burnout syndrome (BO). However, no prevalence studies were conducted over the period studied.

Conclusion LT can present many occupational pathologies. Few articles studied the prevalence of MSD and BO.

\section{INFECTIONS DISEASE AMONG PROFESSIONAL DIVERS: REVIEW OF LITERATURE 2016}

\begin{abstract}
${ }^{1,2}$ R Pougnet, ${ }^{1,3}$ L Pougnet, ${ }^{4}$ I Alliot, ${ }^{1} \mathrm{D}$ Lucas, ${ }^{1,2} \mathrm{~B}$ Loddé, ${ }^{1} \mathrm{JD}$ Dewitte. ${ }^{1}$ French Society of Martim Medicine (SFMM), France; ${ }^{2}$ EA 4686, Ethic, Professionalism and Health, European University of Brittany, Brest, France; ${ }^{3}$ Medical Laboratory, Military Hospital, ClermontTonnerre, Brest, France; ${ }^{4}$ Environmental Laboratory of French Navy, Brest, France
\end{abstract}

\subsection{6/oemed-2018-ICOHabstracts. 1098}

Introduction The occupational divers are subject to numerous risks. For instance, divers can get infections. We review the infectious diseases in professional divers.

Materials and methods This is a literature review until 30/05/ 2017. The research was conducted on Medline and Scopus databases, in French and English languages.

Results Fifteen papers report cases of infections in professional divers. These are mainly skin infections, but also ENT and ophthalmological infections.

Discussion-conclusion According to data collected, infections among professional divers are quite rare. These diseases are not specific to the workplace, and are comparable with data on recreational diving. Prevention is mainly based on hygiene and equipment maintenance.

\section{ANXIETY AND MOOD DISORDERS AMONG JUNIOR DOCTORS}

R Pougnet, L Pougnet. Teachnig Hospital of Brest, Brest, France

\subsection{6/oemed-2018-ICOHabstracts.1099}

Introduction The junior doctors are subject to several professional constraints. This study aims to assess the prevalence of anxiety, depressive disorder and burnout (BO) and their risk factors.

Material and method This is a review of the literature between 01/01/2004 and 31/10/2014. A prevalence were calculated for a virtual population.

Results The prevalence of anxiety disorders was between $15.8 \%$ and $87 \%$ depending on the study; that of mood disorder was between $16.3 \%$ and $48 \%$. The prevalences of virtual populations were $32.5 \%$ and $21.7 \%$ respectively. BO prevalence was between $10 \%$ and $80.2 \%$ while prevalence for virtual population was $33.2 \%$. Several studies have shown that working hours, study or work relations were risk factors.

Conclusion The data in the literature ranged from one study to another. Some risk factors have been shown.

\section{NEW CONCEPTS OF DISABILITY AND IMPAIRMENT APPLIED IN THE OCCUPATIONAL HEALTH PHYSICIAN EVALUATION: IS THERE A CONFLICT WITH BIOETHICS PRINCIPLES?}

1,2,3,4 RN Rocha* ${ }^{2} \mathrm{JC}$ Bezerra, ${ }^{4} \mathrm{JC}$ Ferreira, ${ }^{4} \mathrm{FB}$ Tavares, ${ }^{5,6,7} \mathrm{AG}$ Silva. ${ }^{1}$ International Commission on Occupational Health, Milano, Italy; ${ }^{2}$ Associação Nacional de Medicina do Trabalho, São Paulo, Brazil; ${ }^{3}$ Associação Brasiliense de Medicina do Trabalho, Brasilia, Brazil; ${ }^{4}$ Conselho Federal de Medicina, Brasilia, Brazil; ${ }^{5}$ Escola Superior de Ciências da Saúde, Brasilia, Brazil; ${ }^{6}$ Associação Psiquiátrica da América Latina, Antigua, Guatemala: ${ }^{7}$ Associação Brasileira de Psiquiatria, Rio de Janeiro, Brazil

\subsection{6/oemed-2018-ICOHabstracts.1100}

Introduction The Industrial Revolution and the great wars have produced generations of mutilated people, set aside to their own devices, without access to education resources, culture, leisure and work. In Brazil and in the world various institutions were created and evolved the legislation seeking to guarantee rights for people with disabilities. Including the quotas in the public tender and special retirement law. The study asks for the conceptual mistake of disability and impairment, and the existence of possible bioethical conflict concerning the principle of beneficence, where expert physician does not recognise the declared disability and the principle of justice when the Judge determines that the state take possession the individual without any hindrance in interaction with barriers that obstruct their full participation in society

Methods For that sought to integrative research literature in various research sites on concepts and legislation.

Results This study should be expanded and the experts should apply the IFBrA instrument during the evaluation of candidates with disabilities.

Discussion The study allowed for the analysis of the Brazilian Functionality Index on the candidate's disability evaluation to public service, allowed a critical reflection on the medical expert front act to the principle of beneficence: it isn't a 